\title{
FREQUENCY, DISTRIBUTION AND DETERMINANTS OF HYPERTENSION IN ADULT STROKE POPULATION OF D.I.KHAN DIVISION, PAKISTAN
}

\author{
Nazafatul Ain', Saira Khan', Muhammad Marwat', Nisar Khan³, Iftikhar Ahmad', Farhana Ramzan', \\ Wajeeha Akhtar', Hadia Fakhar', Yabqa Jehan'1, Azalfa Zeb'ㄹ, Maimoona Kundi', Saima Bibi', Musarat \\ Fatima', Amna Raza' \\ Departments of ${ }^{1}$ Community Medicine, ${ }^{2}$ Ophthalmology \& ${ }^{3}$ Medicine, Gomal Medical College, D.I.Khan,
} Pakistan

\begin{abstract}
Background: Global Health Estimates 2015 has shown the stroke as second leading global cause of death and 3rd leading global cause for DALYs for year 2015. The objectives of this study were to determine the frequency, distribution and determinants of hypertension in adult stroke population of D.I.Khan Division, Pakistan.

Materials \& Methods: This cross-sectional study was conducted in Department of Community Medicine, Gomal Medical College, D.I.Khan, Pakistan from February 1, 2017 to April 30, 2017. A sample 217 was selected with margin of error $5.59 \%, 90 \% \mathrm{CL}$ and $50 \%$ prevalence of hypertension in 200,000 adults at risk of stroke population through consecutive sampling. All indoor adult patients of stroke were eligible. Sex, age groups, and residence and presence of hypertension were variables. Frequency and distribution of hypertension were analyzed by count and percentage. Hypotheses for distribution were substantiated by chi-square goodness-of-fit and of association by chi-square test of association.

Results: Out of 217 patients with stroke, $123(56.7 \%)$ were men and 94 (43.3\%) were women, $86(39.6 \%)$ were $\leq 60$ years and 131 (60.4\%) were >60 years, and 105 (48.4\%) were urban and $112(51.6 \%)$ were rural. Frequency of hypertension was 132/217 (60.83\%). Out of 132 patients with hypertension, men were $74(34.10 \%)$, women 58 $(26.73 \%)$, age group $\leq 60$ years $46(21.20 \%),>60$ years $86(39.63 \%)$, urban $72(33.18 \%)$ and rural $60(27.65 \%)$. Presence of hypertension was associated to residence $(p=.023)$ but not to sex $(p=.817)$ and age groups $(p=.072)$.

Conclusion: Frequency of hypertension in adult stroke population of D.I.Khan Division, Pakistan was found to be similar as expected. Frequency was more in men, in older age group (of>60years) and in urban population. The presence of hypertension in adult stroke population of D.I.Khan Division was associated to residence but not to sex and age groups.
\end{abstract}

KEY WORDS: Stroke; Hypertension; Adult; Men: Women; Global Health; Pakistan; Urban Population; Chi-square Test.

This article may be cited as: Ain N, Khan S, Marwat M, Khan N, Ahmad I, Ramzan F, et al. Frequency, distribution and determinants of hypertension in adult stroke population of D.I.Khan Division, Pakistan. Gomal J Med Sci 2019 Jul-Sep; 17 (3):81-9. https://doi.org/10.46903/gjms/17.03.2076

\section{INTRODUCTION}

1.1 Background: Globally stroke is a major health problem. It is a major cause of mortality, disability and

\section{Corresponding Author:}

Dr. Saira Khan

Department of Community Medicine

Gomal Medical College

D.I.Khan, Pakistan

E-mail: sarapocket06@gmail.com

Date Submitted: $\quad 31-07-2018$

Date Revised: $\quad$ 02-05-2019

Date Accepted: $\quad$ 01-06-2019 morbidity in developed communities and is increasing in developing communities. Evidence suggests that in future its burden will certainly increase. ${ }^{1}$

Worldwide in 2013 there were approximately 25.7 million stroke survivors, 6.5 million deaths due to stroke, 113 million DALYs due to stroke and 10.3 million new cases of strokes. ${ }^{2}$

Global Health Estimates 2015 has shown for the year 2000 with world population of $6,122,410,000$ and deaths of $52,134,566$, that stroke was the second leading global cause of death, responsible for $5,406,516$ deaths, amounting to $10.4 \%$ of total deaths ${ }^{3}$, and $5^{\text {th }}$ leading global cause for DALYs, 
with total $124,385,652$ DALYs, amounting to $4.4 \%$ of DALYs due to all causes. ${ }^{4}$ For the year 2015 with world population of $7,344,362,000$ and deaths of $56,441,319$, stroke was the second leading global cause of death, responsible for $6,240,611$ deaths, amounting to $11.1 \%$ of total deaths ${ }^{3}$, and $3^{\text {rd }}$ leading global cause for DALYs with total 139,873,932 DALYs, amounting to $5.2 \%$ of DALYs due to all causes. ${ }^{4}$

Global Health Estimates for Eastern Mediterranean Region has shown for the year 2000 with population of $467,911,000$ and deaths of $3,400,392$, that stroke was the $3^{\text {rd }}$ leading regional cause of death, responsible for 265,376 deaths, amounting to $7.8 \%$ of total deaths ${ }^{3}$, and $5^{\text {th }}$ leading cause for DALYs, with total $7,357,542$ DALYs, amounting to $4.4 \%$ of DALYs due to all causes. ${ }^{4}$ For the year 2015 with population of $643,784,000$ and deaths of $4,023,088$, stroke was the second leading regional cause of death, responsible for 358,435 deaths, amounting to $8.9 \%$ of total deaths ${ }^{3}$, and $3^{\text {rd }}$ leading regional cause for DALYs with total $9,231,021$ DALYs, amounting to $5.2 \%$ of DALYs due to all causes. ${ }^{4}$

Global Health Estimates has shown for the year 2000 with Pakistan estimated population of $138,250,000$ and total deaths of $1,203,200$, that stroke was responsible for estimated 74,100 deaths $^{3}$, and 1,918,900 DALYs. ${ }^{4}$ For the year 2015 with Pakistan estimated population of $188,925,000$ and total deaths of $1,370,800$, that stroke was responsible for estimated 109,200 deaths ${ }^{3}$, and 2,729,600 DALYs. ${ }^{4}$

In Pakistan, estimated annual incidence of stroke is $250 / 100,000$; which means 350,000 new cases per year. ${ }^{5}$

One-quarter of the global adult population is hypertensive and by 2025 , it is likely to increase to $29 \% .{ }^{6}$

As per estimates of National Health Survey of Pakistan, $1999-1994$, approximately $18.9 \%$ adult (15 years) population of Pakistan is hypertensive. ${ }^{7}$

A systematic review for the period from 1990-2017, by Shah et al. ${ }^{8}$ in 2018, including 18 studies and 42,618 participants, showed an overall pooled prevalence of hypertension in adult (15 years) population of Pakistan as $26.34 \%$ (95\% Cl $25.93 \%, 26.75 \%)$.

Hypertension is a major risk factor for both ischemic and hemorrhagic strokes. Increasing blood pressure levels are seen to be positively and continuously related to the risk for stroke. ${ }^{9}$

Data from the China National Stroke Registry, published in 2013, showed that out of 11,560 patients with ischemic stroke, 8409 (72.7\%) had hypertension. ${ }^{10}$

Zuhaid et al. ${ }^{11}$ from Abbottabad, Pakistan in 2013 found hypertension to be the most common risk factor for stroke, affecting 127 out of his 150 (84.7\%) patients.

A study by Khan et al. ${ }^{12}$ from Karachi, Pakistan in
2006-2007, showed 36 out of 55 (65.45\%) patients aging $>25$ years with ischemic stroke to be hypertensive, including 29/55 (52.73\%) males and 7/55 (12.72\%) females.

Basharat et al. ${ }^{13}$ from Lahore, Pakistan in 2000, showed hypertension as a risk factor for stroke in $61 / 100(61 \%)$ cases.

Masood et al. ${ }^{14}$ in 2010-2011 from Mirpur, Azad Kashmir, Pakistan reported 136/200 (68\%) cases of hypertension in stroke.

Khan et al. ${ }^{15}$ from Abbottabad, Pakistan in 20032005 found $51 / 91$ (56.04\%) cases of hypertension in stroke, including $35(38.46 \%)$ males and $16(17.58 \%)$ females, $28(30.77 \%)$ of $21-60$ years and $23(25.27 \%)$ of $60-80$ years.

\subsection{Research Problems, Knowledge Gaps \& Re- search Questions:}

We are unaware of the frequency, distribution by sex, age groups and residence, and determinants (association to sex, age groups and residence) of hypertension in stroke population of D.I.Khan Division, Pakistan. Unawareness of these seven pieces of information are our seven Research Problems. No research documents could be retrieved through online search through different search engines and databases for these seven problems. These are our seven Knowledge Gaps.

What is the frequency, distribution by sex, age groups and residence, and determinants (association to sex, age groups and residence) of hypertension in stroke population of D.I.Khan Division, Pakistan, are our seven Research Questions.

We would place seven probable/ tentative answers to these seven questions from the published literature; these would be our Research Hypotheses. To substantiate our hypotheses, we would collect relevant data from our population (Data Collection), analyze (Data Analysis) and interpret it (Data Interpretation). This would give us the true answers for our Research Questions. Thus the Knowledge Gaps will be filled and the Research Problems will be solved.

These eight logical steps constitute, what is called "Marwat's Logical Trajectory of Research Process", proposed by Dr. Muhammad Marwat, who supervised ours this research project. This trajectory is already applied in few published articles. ${ }^{16,17}$

\subsection{Research Objectives:}

Objective 1 (01): To determine the frequency of hypertension in adult stroke population of D.I.Khan Division, Pakistan.

02-04: To determine the distribution of hypertension by sex, age groups and residence in adult stroke population of D.I.Khan Division, Pakistan

05-07: To determine the association of hypertension to sex, age groups and residence in adult stroke 
population of D.I.Khan Division, Pakistan

\subsection{Research (Null) Hypotheses:}

$\mathbf{H}_{\mathbf{0}} \mathbf{1}$ : The expected and observed frequency of hypertension is same in adult stroke population of D.I.Khan Division, Pakistan

$\mathbf{H}_{0}$ 2: The expected and observed distribution of hypertension by sex is same in adult stroke population of D.I.Khan Division, Pakistan

$\mathbf{H}_{\mathbf{0}}$ 3: The expected and observed distribution of hypertension by age groups is same in adult stroke population of D.I.Khan Division, Pakistan

$\mathbf{H}_{\mathbf{0}} \mathbf{4}$ : The expected and observed distribution of hypertension by residence is same in adult stroke population of D.I.Khan Division, Pakistan

$\mathbf{H}_{\mathbf{0}} \mathbf{5}$ : There is no association between the presence of hypertension and sex in adult stroke population of D.I.Khan Division, Pakistan

$\mathbf{H}_{0}$ 6: There is no association between the presence of hypertension and age groups in adult stroke population of D.I.Khan Division, Pakistan

$\mathbf{H}_{0} 7$ : There is no association between the presence of hypertension and residence in adult stroke population of D.I.Khan Division, Pakistan

\subsection{Operational definitions}

Stroke: Stroke is defined by the WHO as "rapidly developing clinical signs of focal (at times global) disturbance of cerebral function, lasting more than 24 hours or leading to death with no apparent cause other than that of vascular origin". The term global is applied to patients in deep coma and to those with subarachnoid haemorrhage..$^{18}$

Hypertension: A patient was labeled as hypertensive "if his blood pressure was $\geq 140 / 90 \mathrm{~mm} \mathrm{Hg}$ on repeated measurements during the hospitalization or patient was on antihypertensive medication". ${ }^{10}$

Adult: As defined by WHO "an adult is a person older than 19 years of age unless national law defines a person as being an adult at an earlier age". ${ }^{19}$

\section{MATERIALS AND METHODS}

2.1 Design, Settings \& Duration: This cross-sectional study was conducted in the Department of Community Medicine, Gomal Medical College, D.I.Khan, Pakistan from February 1, 2017 to April 30, 2017. This research project was a part of curriculum of Community Medicine for $4^{\text {th }}$ year MBBS studies and was supervised by $\mathrm{MM}$ and co-supervised by NK \& IA. Here all the three important components of epidemiological research are covered; frequency, distribution and determinants of a disease in a specified population. Patient's files of Medical ICU of DHQ Teaching Hospital, D.I.Khan for the period from January 1, 2016 to December 31, 2016 were included.

\subsection{Population, Sample size \& technique and}

Sample selection: The catchment area of our hospital is D.I.Khan Division, including districts D.I.Khan \& Tank and tribal areas of South Waziristan Agency \& Frontier Region Darazinda. Total population of D.I.Khan Division was estimated to be around 2.7 million in the year 2016. Adult hypertensive population at risk of stroke was assumed to 200,000 .

Out of this 200,000 population, a sample size of 217 was selected through Raosoft ${ }_{\circledast}^{20}$ an online sample size calculator, with margin of error $5.59 \%, 90 \% \mathrm{CL}$ and prevalence of hypertension as $50 \%$ in adult stroke population. The sampling technique was consecutive non-probability.

All indoor adult ( $>19$ years) patients of stroke were eligible. Those with other neurological symptoms mimicking stroke were excluded.

2.3 Data Collection Plan: Sex (men \& women), age groups (up to 60 years and $>60$ years), and residence (urban and rural) were demographic while presence of hypertension (yes and no) was a research variable. All these variables were measured on nominal scale. Presence of hypertension was a dependent variable, while sex, age groups and residence each was an independent variable for tests of association.

\subsection{Data Analysis Plan:}

2.4.1 Descriptive Statistics \& Estimation of Parameters: The sample will be categorized by sex, age groups and residence as count and percentage. The frequency and distribution of hypertension will be given as count and percentage for the sample and as confidence interval $(\mathrm{Cl})$ for proportion for the population at $95 \%$ confidence level $(C L)$ using the normal distribution approximation for the binomial distribution through an online statistical calculator. ${ }^{21}$

2.4.2 Hypotheses Testing: The expected and observed frequency and expected and observed distribution by sex, age group and residence will be testified through chi-square goodness of fit test.22,23 The association of the presence of hypertension and sex, age group and residence will be testified by chi-square test of association. ${ }^{22,23}$ Observed counts, expected counts, their difference, chi-square value, degree of freedom and significance ( $p$-value) will be given for each test separately using an online statistical calculator. ${ }^{24}$ All these tests will be performed at alpha .05.

\section{RESULTS}

3.1 Descriptive Statistics \& Estimation of Parameters: Out of 217 patients with stroke, $123(56.7 \%)$ were men and 94 (43.3\%) were women, 86 (39.6\%) were up to 60 years and $131(60.4 \%)$ were more than 60 years, and 105 (48.4\%) were urban and 112 $(51.6 \%)$ were rural. 
3.1.1 Frequency of hypertension in adult stroke population: The frequency of hypertension in the sample was $132 / 217(60.83 \%)$ with $95 \% \mathrm{Cl}$ as $54.33 \%$ $67.32 \%$. It means that the estimated prevalence of hypertension in adult stroke population of D.I.Khan Division lies between $54.33 \%$ and $67.32 \%$. (Table 3.1.1)

3.1.2 Distribution of positive cases of hypertension in adult stroke population by sex, age group \& residence: The distribution of positive cases of hypertension by sex, age group and residence in adult stroke population of D.I.Khan Division is shown in Table 3.1.2. Here the frequency of hypertension in stroke in sample and its estimated prevalence in population is more in men, in age $>60$ years, and in urban patients.

\subsection{Hypotheses Testing:}

3.2.1 Expected vs observed frequency of hypertension in adult stroke population $\left(\mathrm{H}_{0} 1\right)$ :
Here the presence of hypertension in adult stroke population of D.I.Khan Division was expected to be $51(56.04 \%)$ positive cases versus 40 negative cases $(43.96 \%)$ of hypertension in 91 patients of stroke, from a study by Khan et al. ${ }^{15}$ from Abbottabad, Pakistan in 2003-2005.

The observed counts of our study were 132:85 out of 217 stroke patients. For comparison, the expected counts were calculated to be 122:95 for a sample of 217. The difference between these expected and observed counts was analyzed through chi-square goodness of fit test at alpha .05. With p-value more than alpha, $\mathrm{H}_{0} 1$ was proved to be true and hence accepted, showing that there is good fit between the expected and observed counts.

In simple words, the frequency of hypertension in adult stroke population of D.I.Khan Division $60.83 \%$ was similar to what we expected from the literature 56.04\%. (Table 3.2.1)

Table 3.1.1: Frequency of hypertension in sample and prevalence in adult stroke population of D.I.Khan Division, Pakistan $(n=217)$

\begin{tabular}{|l|l|c|c|c|c|}
\hline \multirow{2}{*}{ Variables } & \multirow{2}{*}{ Attributes } & \multicolumn{2}{|c|}{ Sample Statistics } & \multicolumn{2}{c|}{$95 \%$ Cl for Proportion } \\
\cline { 2 - 5 } & & Count & Percentage & Lower & Upper \\
\hline \multirow{3}{*}{$\begin{array}{l}\text { Presence of hy- } \\
\text { pertension }\end{array}$} & Yes & 132 & 60.83 & 54.33 & 67.32 \\
\cline { 2 - 6 } & No & 85 & 39.17 & 32.68 & 45.66 \\
\cline { 2 - 6 } & Total & 217 & 100.00 & \multicolumn{2}{c|}{ Population Parameters } \\
\hline
\end{tabular}

Table 3.1.2: Distribution of positive cases of hypertension by sex, age group and residence in adult stroke population of D.I.Khan Division, Pakistan $(n=132 / 217)$

\begin{tabular}{|l|l|c|c|c|c|c|}
\hline \multirow{2}{*}{ Variables } & \multirow{2}{*}{ Attributes } & \multirow{2}{*}{ Sample size } & \multicolumn{2}{|c|}{ Hypertension Yes } & \multicolumn{2}{|c|}{ 95\% Cl for Proportion } \\
\cline { 3 - 7 } & & & Count & Percentage & Lower & Upper \\
\hline \multirow{2}{*}{ Sex } & Men & 123 & 74 & 34.10 & 27.79 & 40.41 \\
\cline { 2 - 7 } & Women & 94 & 58 & 26.73 & 20.84 & 32.62 \\
\hline \multirow{2}{*}{ Age group } & Up to 60 years & 86 & 46 & 21.20 & 15.76 & 26.64 \\
\cline { 2 - 7 } &.$>60$ years & 131 & 86 & 39.63 & 33.12 & 46.14 \\
\hline \multirow{2}{*}{ Residence } & Urban & 105 & 72 & 33.18 & 26.92 & 39.44 \\
\cline { 2 - 7 } & Rural & 112 & 60 & 27.65 & 21.70 & 33.60 \\
\hline & Total & 217 & 132 & 60.83 & 54.33 & 67.32 \\
\hline
\end{tabular}

Table 3.2.1: Expected vs observed frequency of hypertension in adult stroke population of D.I.Khan Division, Pakistan $(n=217)$

\begin{tabular}{|l|l|c|c|c|c|c|c|c|c|}
\hline Variable & Attributes & $\mathrm{O}$ & $\mathrm{E}$ & $\mathrm{O}-\mathrm{E}$ & $(\mathrm{O}-\mathrm{E}) 2$ & $(\mathrm{O}-\mathrm{E}) 2 / \mathrm{E}$ & $\square^{2}$ & d.f. & P-value \\
\hline \multirow{3}{*}{$\begin{array}{l}\text { Presence of hy- } \\
\text { pertension }\end{array}$} & Yes & 132 & 122 & 10 & 100 & 0.819 & 1.871 & 1 & .1712 \\
\cline { 2 - 9 } & No & 85 & 95 & -10 & 100 & 1.052 & $\mathrm{H}_{0} 1$ accepted at alpha 0.05 \\
\cline { 2 - 9 } & Total & 217 & 217 & \multicolumn{6}{|c|}{ Chi-square goodness of fit test with Yates correction } \\
\hline
\end{tabular}

$\mathrm{O}=$ Observed Counts, $\mathrm{E}=$ Expected Counts, $\mathrm{\square}^{2}=$ Chi-square value, d.f. $=$ Degree of freedom 
3.2.2 Expected vs observed distribution of positive cases of hypertension by sex in adult stroke population $\left(\mathbf{H}_{0} \mathbf{2}\right)$ : Here the expected distribution of positive cases of hypertension by sex (men: women) in adult stroke population of D.I.Khan Division was 35:16 (38.46\%:17.58\%) out of 51 (56.04\%) positive cases from a sample of 91 stroke patients, from a study by Khan et al. ${ }^{15}$ from Abbottabad, Pakistan in 2003-2005.

The observed counts from our study were $74: 58$ out of 132 positive cases from a sample of 217 stroke patients. For comparison, the expected counts were calculated to be $91: 41$ for a sample of 132 . The difference between these expected and observed counts was analyzed through chi-square goodness of fit test at alpha .05. With p-value less than alpha, $\mathrm{H}_{0} 2$ was proved to be false and hence rejected, showing that there is no good fit between the expected and observed counts. In simple words, the observed frequency of hypertension in our population in men $(34.10 \%)$ was significantly lower than what we expected $(38.46 \%)$ from the literature, and vice versa for women; the observed frequency of hypertension in our population in women (26.73\%) was significantly higher than what we expected from the literature (17.58\%). (Table 3.2.2)

3.2.3 Expected vs observed distribution of positive cases of hypertension by age groups in adult stroke population $\left(\mathrm{H}_{0} 3\right)$ : Here the expected distribution of positive cases of hypertension by age groups ( $\leq 60$ years: $>60$ years) in adult stroke population of D.I.Khan Division was 28:23 (30.77\%:25.27\%) out of $51(56.04 \%)$ positive cases from a sample of 91 stroke patients, from a study by Khan et al. ${ }^{15}$ from Abbottabad, Pakistan in 2003-2005.
The observed counts from our study were 46:86 (21.20\%:39.63\%) out of 132 positive cases from a sample of 217 stroke patients. For comparison, the expected counts were calculated to be $72: 60$ for a sample of 132 . The difference between these expected and observed counts was analyzed through chi-square goodness of fit test at alpha .05 . With $\mathrm{p}$-value less than alpha, $\mathrm{H}_{0} 3$ was proved to be false and hence rejected, showing that there is no good fit between the expected and observed counts. In simple words, the observed frequency of hypertension in our population in age group $\leq 60$ years $(21.20 \%)$ was significantly lower than what we expected $(30.77 \%)$ from the literature and vice versa for age group >60 years; the observed frequency of hypertension in our population in age group $>60$ years $(39.63 \%)$ was significantly higher than what we expected from the literature (25.27\%). (Table 3.2.3)

3.2.4 Expected vs observed distribution of positive cases of hypertension by residence in adult stroke population $\left(\mathrm{H}_{0} 4\right)$ : As no corresponding study was available from literature, so the expected distribution of positive cases of hypertension by residence (urban: rural) in adult stroke population of D.I.Khan Division was 132/2= 66:66 (30.415\%:30.415\%).

The observed counts from our study were $72: 60$ out of 132 positive cases from a sample of 217 stroke patients. The difference between these expected and observed counts was analyzed through chi-square goodness of fit test at alpha .05. With p-value more than alpha, $\mathrm{H}_{0} 4$ was proved to be true and hence accepted, showing that there is good fit between the expected and observed counts.

In simple words, the observed frequency of hyper-

Table 3.2.2: Expected vs observed distribution of positive cases of hypertension by sex in adult stroke population of D.I.Khan Division, Pakistan $(n=132)$

\begin{tabular}{|l|l|c|c|c|c|c|c|c|l|}
\hline Variable & Attributes & $\mathrm{O}$ & $\mathrm{E}$ & $\mathrm{O}-\mathrm{E}$ & $(\mathrm{O}-\mathrm{E}) 2$ & $(\mathrm{O}-\mathrm{E}) 2 / \mathrm{E}$ & $\square^{2}$ value & d.f. & P-value \\
\hline \multirow{3}{*}{ Sex } & Men & 74 & 91 & -17 & 289 & 3.17 & 10.21 & 1 & .00139 \\
\cline { 2 - 10 } & Women & 58 & 41 & 17 & 289 & 7.04 & $\mathrm{H}_{0} 2$ rejected at alpha 0.05 \\
\cline { 2 - 9 } & Total & 132 & 132 & 00 & \multicolumn{6}{|c|}{ Chi-square goodness of fit test with Yates correction } \\
\hline
\end{tabular}

$\mathrm{O}=$ Observed Counts, $\mathrm{E}=$ Expected Counts, $\square^{2}=$ Chi-square value, d.f. $=$ Degree of freedom

Table 3.2.3: Expected vs observed distribution of positive cases of hypertension by age groups in adult stroke population of D.I.Khan Division, Pakistan $(n=132)$

\begin{tabular}{|l|l|c|c|c|c|c|c|c|c|}
\hline Variable & Attributes & $\mathrm{O}$ & $\mathrm{E}$ & $\mathrm{O}-\mathrm{E}$ & $(\mathrm{O}-\mathrm{E}) 2$ & $(\mathrm{O}-\mathrm{E}) 2 / \mathrm{E}$ & $\square^{2}$ value & d.f. & P-value \\
\hline \multirow{4}{*}{ Age group } & $\leq 60$ years & 46 & 72 & -26 & 676 & 09.39 & 20.66 & 1 & $<.00001$ \\
\cline { 2 - 9 } & $>60$ years & 86 & 60 & 26 & 676 & 11.27 & $\mathrm{H}_{0} 3$ rejected at alpha 0.05 \\
\cline { 2 - 10 } & Total & 132 & 132 & 00 & \multicolumn{6}{|c|}{ Chi-square goodness of fit test with Yates correction } \\
\hline
\end{tabular}

$\mathrm{O}=$ Observed Counts, $\mathrm{E}=$ Expected Counts, $\square^{2}=$ Chi-square value, d.f. $=$ Degree of freedom 
tension in urban and rural populations is similar to what we expected from the literature. (Table 3.2.4)

3.2.5 Association of presence of hypertension to sex in adult stroke population $\left(\mathrm{H}_{0} 5\right)$ : Presence of hypertension in stroke as a research/ dependent variable was cross-tabulated by sex as a demographic/ independent variable. With $p$-value $>$ alpha, $\mathrm{H}_{0} 5$ was proved to be true and hence accepted, showing that hypertension was not associated with sex. (Table 3.2.5)

3.2.6 Association of presence of hypertension to age groups in adult stroke population $\left(\mathrm{H}_{0} 6\right)$ : Presence of hypertension in stroke as a research/ dependent variable was cross-tabulated by age groups as a demographic/ independent variable. With $\mathrm{p}$-value $>$ alpha, $\mathrm{H}_{0} 6$ was proved to be true and hence accepted, showing that hypertension was not associated with age groups. (Table 3.2.6)

3.2.7 Association of presence of hypertension to residence in adult stroke population $\left(\mathrm{H}_{0} 7\right)$ : Presence of hypertension in stroke as a research/ dependent variable was cross-tabulated by residence as a demographic/ independent variable. With $\mathrm{p}$-value $<$ alpha, $\mathrm{H}_{0} 7$ was proved to be false and hence rejected, showing that hypertension was associated with residence. (Table 3.2.7)

Table 3.2.4: Expected vs observed distribution of positive cases of hypertension by residence in adult stroke population of D.I.Khan Division, Pakistan $(n=132)$

\begin{tabular}{|l|l|c|c|c|c|c|c|c|c|}
\hline Variable & Attributes & $\mathrm{O}$ & $\mathrm{E}$ & $\mathrm{O}-\mathrm{E}$ & $(\mathrm{O}-\mathrm{E}) 2$ & $(\mathrm{O}-\mathrm{E}) 2 / \mathrm{E}$ & $\mathrm{\square}^{2}$ value & d.f. & P-value \\
\hline \multirow{2}{*}{ Residence } & Urban & 72 & 66 & 06 & 36 & 0.55 & 1.090 & 1 & .2962 \\
\cline { 2 - 9 } & Rural & 60 & 66 & -06 & 36 & 0.55 & $\mathrm{H}_{0} 4$ accepted at alpha 0.05 \\
\hline \multirow{2}{*}{} & Total & 132 & 132 & 00 & \multicolumn{6}{|c|}{$\begin{array}{c}\text { Chi-square goodness of fit test with Yates cor- } \\
\text { rection }\end{array}$} \\
\hline
\end{tabular}

$\mathrm{O}=$ Observed Counts, $\mathrm{E}=$ Expected Counts, $\mathrm{\square}^{2}=$ Chi-square value, d.f. $=$ Degree of freedom

Table 3.2.5: Association of presence of hypertension to sex in adult stroke population of D.I.Khan Division, Pakistan $(n=217)$

\begin{tabular}{|l|l|l|c|c|c|c|}
\hline Variables & HTN-Yes & HTN- No & \multirow{2}{*}{ Rows Total } & \multirow{2}{*}{ Chi-square value } & d.f. & P-value \\
\cline { 1 - 3 } Sex & $\mathrm{O}(\mathrm{E})$ & $\mathrm{O}(\mathrm{E})$ & 123 & 0.053 & 1 & 0.817 \\
\hline Men & $74(74.82)$ & $49(48.18)$ & 94 & \multicolumn{2}{|c|}{$\mathrm{H}_{0} 5$ accepted at alpha 0.05} \\
\hline Women & $58(57.18)$ & $36(36.82)$ & 217 (Grand Total) & \multicolumn{2}{|c|}{ Chi-square test of association } \\
\hline
\end{tabular}

HTN $=$ Presence of hypertension, $\mathrm{O}=$ Observed Counts, $\mathrm{E}=$ Expected Counts, d.f. $=$ Degree of freedom

Table 3.2.6: Association of presence of hypertension to age groups in adult stroke population of D.I.Khan Division, Pakistan $(n=217)$

\begin{tabular}{|c|c|c|c|c|c|c|}
\hline Variables & HTN-Yes & HTN- No & \multirow{2}{*}{ Rows Total } & \multirow{2}{*}{ Chi-square value } & \multirow{2}{*}{ d.f. } & \multirow{2}{*}{ P-value } \\
\hline Age groups & $\mathrm{O}(\mathrm{E})$ & $\mathrm{O}(\mathrm{E})$ & & & & \\
\hline$\leq 60$ years & $46(52.31)$ & 40 (33.69) & 86 & 3.222 & 1 & 0.072 \\
\hline$>60$ years & $86(79.69)$ & $45(51.31)$ & 131 & \multicolumn{3}{|c|}{$\mathrm{H}_{0} 6$ accepted at alpha 0.05} \\
\hline Columns Total & 132 & 85 & 217 (Grand Total) & \multicolumn{3}{|c|}{ Chi-square test of association } \\
\hline
\end{tabular}

HTN $=$ Presence of hypertension, $\mathrm{O}=$ Observed Counts, $\mathrm{E}=$ Expected Counts, d.f. $=$ Degree of freedom

Table 3.2.7: Association of presence of hypertension to residence in adult stroke population of D.I.Khan Division, Pakistan $(n=217)$

\begin{tabular}{|l|l|l|c|c|c|c|}
\hline Variables & HTN-Yes & HTN- No & \multirow{2}{*}{ Rows Total } & Chi-square value & d.f. & P-value \\
\cline { 1 - 3 } Residence & O (E) & O (E) & 105 & 5.117 & 1 & 0.023 \\
\hline Urban & $72(63.87)$ & $33(41.13)$ & 112 & $\mathrm{H}_{0} 7$ rejected at alpha 0.05 \\
\hline Rural & $60(68.13)$ & $52(43.87)$ & 217 (Grand Total) & \multicolumn{2}{|c|}{ Chi-square test of association } \\
\hline
\end{tabular}

$\mathrm{HTN}=$ Presence of hypertension, $\mathrm{O}=$ Observed Counts, $\mathrm{E}=$ Expected Counts, d.f. $=$ Degree of freedom 


\section{DISCUSSION}

4.1 Frequency of hypertension in adult stroke population: The frequency of hypertension in our sample was $60.83 \%$ (132/217) with estimated prevalence in adult stroke population of D.I.Khan Division between $54.33 \%$ and $67.32 \%$.

Similar prevalence to our study was shown by Khan et al. ${ }^{12}$ from Karachi, Pakistan in 2006-2007 as $65.45 \%(36 / 55)$ in patients aging $>25$ years with ischemic stroke, Basharat et al. ${ }^{13}$ from Lahore, Pakistan in 2000 as $61 \%$ (61/100 cases) and Khan et al. ${ }^{15}$ from Abbottabad, Pakistan in 2003-2005 as 56.04\% (51/91) cases of hypertension in stroke.

Higher prevalence to our study was shown by data from the China National Stroke Registry ${ }^{10}$, published in 2013 as $72.7 \%(8409 / 11,560)$ in patients with ischemic stroke, Zuhaid et al. ${ }^{11}$ from Abbottabad, Pakistan in 2013 as 84.7\% (127/150) and by Masood et al. ${ }^{14}$ in 2010-2011 from Mirpur, Azad Kashmir, Pakistan as 68\% (136/200).

The observed frequency of hypertension in adult stroke population of D.I.Khan Division $60.83 \%$ was similar to what we expected from the literature $56.04 \%$, from a study by Khan et $a l .{ }^{15}(p=.1712)$ from Abbottabad, Pakistan in 2003-2005 (Table 3.2.1). No relevant studies with hypothesis testing could be retrieved from literature for comparison.

4.2 Distribution of positive cases of hypertension in adult stroke population by sex: The prevalence of hypertension in stroke was higher for men $34.10 \%$ (27.79\%-40.41\%) than women $26.73 \%$ (20.84\%$32.62 \%)$ in our population.

Similar figures are reported by Khan et al. ${ }^{12}$ from Karachi, Pakistan in 2006-2007, showing 52.73\% (29/55) prevalence for men and $12.72 \%$ (7/55) prevalence for women, out of 55 patients with ischemic stroke. The authors have shown $67.4 \%$ prevalence for men and $58.3 \%$ for women, totaling to $125.7 \%$, which of course cannot be correct. The authors have calculated percentage as 29 men out of 36 hypertension positive cases and 7 women out of 36 hypertension positive cases, hence it went wrong. We have calculated percentage for men as 29 out of total sample of 55 stroke patients and for women as 7 out of 55 .

Similar to our results were from Khan et al..$^{15}$ from Abbottabad, Pakistan in 2003-2005, showing 38.46\% (35/91) prevalence for men and 17.58\% (16/91) prevalence for women. The authors have shown $68.63 \%$ prevalence for men and $31.37 \%$ for women, totaling to $100 \%$, which of course cannot be correct as all the patients with stroke are not hypertensive, but only 51 out 91 (56.04\%) are hypertensive. The authors have calculated percentage as 35 men out of 51 (68.63\%) hypertension positive cases and 16 women out of 51 (31.37\%) hypertension positive cases, hence it went wrong. We have calculated percentage as 35 men with hypertension out of total sample of 91 (38.46\%) stroke patients and 16 women out of 91 (17.58\%) stroke patients.

The observed frequency of hypertension in in adult stroke population of D.I.Khan Division in men $(34.10 \%)$ was significantly lower than what we expected $(38.46 \%)$ from the literature, and vice versa for women; the observed frequency of hypertension in our population in women $(26.73 \%)$ was significantly higher than what we expected from the literature (17.58\%) from a study by Khan et al..$^{15}(p=.00139)$ from Abbottabad, Pakistan in 2003-2005 (Table 3.2.2). No relevant studies with hypothesis testing could be retrieved from literature for comparison.

4.3 Distribution of positive cases of hypertension in adult stroke population by age groups: The prevalence of hypertension in stroke was higher $39.63 \%(33.12 \%-46.14 \%)$ for age group $>60$ years than $21.20 \%(15.76 \%-26.64 \%)$ for age group $\leq 60$ years in our population.

Contrary to our results are from Khan et al. ${ }^{15}$ from Abbottabad, Pakistan in 2003-2005, who found 51/91 (56.04\%) cases of hypertension in stroke, with higher prevalence for age group 20-60 years as $30.77 \%$ (28/91) than age group $61-80$ years as $25.27 \%$ (23/91). Here three groups of 20-40, 41-50 \& 51-60 years were combined together for comparison to our one group of $\leq 60$ years and two groups of 61-70 and $71-80$ were combined together to compare to our one group of $>60$ years.

The observed frequency of hypertension in adult stroke population of D.I.Khan Division in age group $\leq 60$ years $(21.20 \%)$ was significantly lower than what we expected $(30.77 \%)$ from the literature and vice versa for age group $>60$ years; the observed frequency of hypertension in our population in age group $>60$ years $(39.63 \%)$ was significantly higher than what we expected from the literature (25.27\%) from a study by Khan et al. ${ }^{15}(p=<.00001)$ from Abbottabad, Pakistan in 2003-2005 (Table 3.2.3). No relevant studies with hypothesis testing could be retrieved from literature for comparison.

4.4 Distribution of positive cases of hypertension in adult stroke population by residence: The prevalence of hypertension in stroke was higher $33.18 \%$ (26.92\%-39.44\%) for urban (72/132) than $27.65 \%$ (21.70\%-33.60\%) for rural (60/132) population in our study.

As no corresponding study was available from literature, so the expected distribution of positive cases of hypertension by residence (urban: rural) in adult stroke population of D.I.Khan Division was taken as equal i.e. 66:66 (132/2) (30.415\%:30.415\%).

The observed frequency of hypertension in adult stroke population of D.I.Khan Division in urban $(33.18 \%)$ and rural $(27.65 \%)$ was similar $(p=.2962)$ to what we expected frequency for urban $(30.415 \%)$ 
and rural (30.415\%), (Table 3.2.4). No relevant studies with hypothesis testing could be retrieved from literature for comparison.

4.5 Association of presence of hypertension to sex, age groups and residence in adult stroke population: There was no association between the presence of hypertension and sex and the presence of hypertension and age groups. There was association between the presence of hypertension and residence in adult stroke population of D.I.Khan Division. No relevant studies could be retrieved from literature for comparison.

\section{CONCLUSION}

The frequency of hypertension in adult stroke population of D.I.Khan Division, Pakistan was found to be similar to as expected. The frequency was more in men, more in older age group (of $>60$ years) and more in urban population. The presence of hypertension in adult stroke population of D.I.Khan Division was associated to residence but not to sex and age groups.

\section{REFERENCES}

1. Kalache A, Aboderin I. Stroke: the global burden. Health Policy Plan [serial online] 1995 Mar [cited 2017 May 22];10(1):1-21. https://doi.org/10.1093/ heapol/10.1.1

2. Feigin VL, Krishnamurthi RV, Parmar P, Norrving B, Mensah GA, Bennett DA, et al. Update on the global burden of ischemic and hemorrhagic stroke in 1990-2013: the GBD 2013 study. Neuroepidemiology [serial online] 2015 Oct 28 [cited 2017 May 23]; 45(3):161-76. https://doi. org/10.1159/000441085

3. Global Health Estimates 2015: Deaths by cause, age, sex, by country and by region, 2000-2015. Geneva, World Health Organization 2016 [cited 2017 May 22]. Available from: http://www.who. int/healthinfo/global_burden_disease/estimates/ en/index1.html

4. Global Health Estimates 2015: Disease burden by cause, age, sex, by country and by region, 2000-2015. Geneva, World Health Organization 2016 [cited 2017 May 22]. Available from:http:// www.who.int/healthinfo/global_burden_disease/ estimates/en/index2.html

5. Pakistan Stroke Society. Information about stroke: How many stroke patients are there in Pakistan? Pakistan Stroke Society. Available at: http://www. pakstroke.com/

6. Kearney PM, Whelton M, Reynolds K, et al. Global burden of hypertension: analysis of worldwide data. Lancet 2005;365(9455):217-23. https://doi. org/10.1016/S0140-6736(05)17741-1

7. NHSP. Pakistan Medical Research Council, Pakistan National Health Survey 1990-1994. Pakistan Medical Research Council publication ISBN 969499-000. Islamabad, Pakistan 1990-1994.

8. Shah N, Shah Q, Shah AJ. The burden and high prevalence of hypertension in Pakistani adolescents: a meta-analysis of the published studies. Archives Public Health 2018;76:20. https://doi. org/10.1186/s13690-018-0265-5

9. WHO. Global Health Observatory (GHO) data. Raised blood pressure: situation and trends [Internet]. World Health Organization; Geneva 2017. [cited 2017 May 17]. Available from. http://who. int/gho/ncd/risk_factors/blood_pressure_prevalence_text/en/

10. Wang $\mathrm{Y}, \mathrm{Xu} \mathrm{J}$, Zhao X, Wang D, Wang C, Liu L, et al. Association of hypertension with stroke recurrence depends on ischemic stroke subtype. Stroke [serial online] 2013 May 1 [cited 2017 May 9]; 44(5):1232-7.doi: 10.1161/STROKEAHA.111.000302. https://doi.org/10.1161/ STROKEAHA.111.000302

11. Zuhaid M, Salman, Chawla JA, Farooq U, Ahmad A, Khan S, Asfandiyar M. Frequency of modifiable risk factors in stroke patients. J Ayub Med Coll Abbottabad 2014; 26(2): 235-8.

12. Khan NI, Naz L, Mushtaq S, Rukh L, Ali S, Hussain Z. Ischemic stroke: prevalence of modifiable risk factors in male and female patients in Pakistan. Pak J Pharma Sci 2009 Jan;22 (1): 62-7.

13. Basharat RA, Yousuf M, Iqbal J, Khan MM. Frequency of known risk factors for stroke in poor patients admitted to Lahore General Hospital in 2000. Pak J Med Sci 2002 Oct-Dec; 18 (4): 280-3.

14. Masood CT, Hussain M, Rehman AU, Abbasi S. Clinical presentation, risk factors and outcome of stroke at a district level teaching hospital. J Ayub Med Coll Abbottabad 2013; 25 (1-2): 49-51.

15. Khan J, Attique-ur-Rehman, Shah A A, Jielani A. Frequency of hypertension in stroke patients presenting at Ayub Teaching Hospital. J Ayub Med Coll Abbottabad. 2006 Jan-Mar;18(1):59-61. Available at: http://www.ayubmed.edu.pk/JAMC/ PAST/18-1/15Jehangir\%20AP.pdf

16. Shah S, Basharat A, Shah M, Marwat M, Billah M, Ali SM. Frequency, distribution and presentation of hypocalcemia in B-thalassemia major. Gomal J Med Sci 2018 Jan-Mar;16(1):2-8. https://doi. org/10.46903/gjms/16.01.1446

17. Shah HU, Gul H, Khan R, Marwat M. Urethrocutaneous fistula following Snodgrass versus two stage Aivar Bracka repair of distal penile hypospadias in male children: a randomized control trial. Gomal J Med Sci 2018 Apr-Jun;16(2):54-8. https://doi.org/10.46903/ gjms/16.02.1284

18. Hatano S. Experience from a multicentre stroke register: a preliminary report. Bull World Health Organ 1976; 54(5): 541-53. Available at: https://www.ncbi.nlm.nih.gov/pmc/articles/ PMC2366492/?page $=1$

19. WHO. HIV/AIDS. Definition of key terms [Internet]. World Health Organization; Geneva 2013. [cited 2017 Jan 17]. Available at: http://www.who.int/ hiv/pub/guidelines/arv2013/intro/keyterms/en/

20. Raosoft ${ }^{\circledR}$ online sample size calculator [Inter- 
net]. Raosoft Inc., Seattle, Washington 2004. [accessed 2017 Jan 17]. Available from:www. raosoft.com/samplesize.html

21. Statistics Kingdom. Proportion confidence interval calculator [internet]. Statistics Kingdom; Melbourne, Australia 2007. [accessed 2017 Oct 12]. Available at: http://www.statskingdom. com/41_proportion_confidence_interval.html
22. Zar JH. Biostatistical Analysis. 5th ed. New York: Prentice-Hall, Inc.

23. Daniel WW. Biostatistics: A Foundation for Analysis in the Health Sciences. 7th ed. Singapore: John Wily; 2005

24. Social Science Statistics. Statistical Tests Calculators [Internet]. [accessed 2017 Oct 12]. Available from: http://www.socscistatistics.com/tests/

\section{CONFLICT OF INTEREST \\ Authors declare no conflict of interest. GRANT SUPPORT AND FINANCIAL DISCLOSURE None declared.}

\section{AUTHORS' CONTRIBUTION}

The following authors have made substantial contributions to the manuscript as under:

Conception or Design:

NA, SK, MM, NK, IA

Acquisition, Analysis or Interpretation of Data:

Manuscript Writing \& Approval:

NA, SK, MM, NK, IA, FR, WA, HF, YJ

NA, SK, MM, NK, IA, AZ, MK, SB, MF, AR

All the authors agree to be accountable for all aspects of the work in ensuring that questions related to the accuracy or integrity of any part of the work are appropriately investigated and resolved. 